\title{
Exploration on Pipa Teaching and Performance under the Guidance of Musical Aesthetics
}

\author{
Zhan Jinyi \\ School of Music, Shaanxi Normal University \\ hunter2011@foxmail.com
}

Keywords: Pipa teaching, Aesthetics; appreciation concept; Teaching and performance

\begin{abstract}
With thousands of years' development, the art of Pipa inherits the aesthetic thoughts of traditional Chinese music as well as the traditional culture of China. In early period, since musical aesthetics are deeply affected by Confucius and Taoism, the musical appreciation of Pipa intends to reach the harmony of human beings and nature. Since ancient times, the forms, shapes and development of Pipa music are deeply affected by traditional Chinese aesthetics. Nowadays, with the constant development and advancement of society, Pipa is affected by foreign cultures which make its development diverse and performance more professional. On the basis of it, since Pipa belongs to traditional Chinese instrument, it still maintains its original national quality despite its absorbing the nutrition from foreign culture. During the performance and teaching of Pipa, what requires our exploration and reflection is to build up correct Pipa aesthetic by students, improve their aesthetical appreciation during the further teaching of each Pipa teachers.
\end{abstract}

\section{Introduction}

After a thousand years development, the art of Pipa forms its unique artistic pattern with the long-lasting time. Pipa music is affected by traditional Chinese musical aesthetics, which can make the music more colorful. Nowadays, as an advanced Pipa performer, to further promote and development Pipa music and make more people understand the unique art of Pipa music is what a Pipa music performer or fonder should do. Under the guidance of musical aesthetics, at the same of making students accept the performance skills of Pipa, teachers should also help students appreciate the artistic glamour of Pipa music from the perspectives of aesthetics and help every student perform unique Pipa music.

\section{Influence of musical aesthetics on the teaching and performance of Pipa}

Harmony and difference. The musical aesthetics in Confucius refers to harmony and further develops to mediocre which means the ideal state of musical aesthetics. The main meaning is that music is everywhere. Listeners should integrate the inner feelings with the external performance so as to present the mediocre state. However, Taoism advocates the harmony of heaven and earth and further creates supreme harmony. For example, in early stage, Laozi pursues nature and steady. So he emphasized the harmony between music created by people and the natural voice, which represents the harmony of human beings and nature. Therefore, harmony has been the requirement of Taoism and Confucius musical aesthetics.

Harmony not only presents the beauty of music but also is the main reason for beauty. The mediocre of Confucius and Supreme Harmony of Taoism all uphold the traditional Chinese musical aesthetics. Though the two are slightly different, the ultimate purpose is to reach the harmony of beauty and goodness as well as the harmony of human beings and nature.

Combination of beauty and virtue. Traditional Chinese musical aesthetic often connects the music aesthetic person with their spiritual quality and moral sentiments so as to realize the real combination of beauty and virtue. Nowadays, most Pipa music are performed according to the themes and present the contents to be played by Pipa music in their titles, which requires that the Pipa performers present strong expressive music and further develop the beauty of Pipa music and bring the enlightenments of goodness to more audiences by proficient, skillful and rich performance 
skills. For example, The Conqueror Unarms, Pipa music, presents the conqueror Xiangyu's manhood and expresses the deep feelings of Xiangyu to Yuji and his villagers with the peculiar voice of Pipa.

Pipa can not only satisfy people's hearing but also express people's inner felling. The combination of beauty and virtue proposed by musical aesthetics has involved virtue and sense of aesthetics into the artistic appreciation. Therefore, during the creation of Pipa music, it should try best to present the combination of beauty and goodness in music.

Unity of heaven and people. Unity of heaven and human beings is a part of the harmony between people and nature in traditional Chinese musical aesthetics. People refer to human beings while heaven refers to the nature. In traditional Chinese culture, people always think that all the things have spirits. Therefore, everything people do to the nature should present respect and care.

During the creation of Pipa music, there should also be the application of nature. For example, Pipa music, Moonlit River In Spring, applies the performing skills of lyric expression through scenery by bring human beings to the natural settings and describes the beautiful national landscape by music so that people are more and more fond of their nation.

The mediocre in traditional Chinese musical aesthetics has diversity. It should combine different objects into a new one under the guidance of mediocre to some extent. And by the concrete analysis of combination of beauty and virtue, harmony of human and nature, Pipa music should combine their own musical development features so as to further look for the beauty of Pipa music in the difference.

\section{Aesthetic features presented in Pipa music}

In traditional classical music of China, Pipa is the most expressive music and its performance also has diversity and uniqueness. With the constant development of society, Pipa music also becomes more and more professional. As traditional national classic music, it also has unique aesthetic features.

Dots and lines. As is known to all, Pipa belongs to Plucked Stringed Instrument in classic instruments of China during which the strings make powerful voice. Many Chinese poems have descriptions for the voice of Pipa. For example, The Pi-pa Player written by Bai Juyi, it says "Chattering and pattering, pattering and chattering, as pearls, large and small, on a jade plate fall", which fully describes the dots features of Pipa voice. Another example is that in "Five strings playing", Bai Juyi says "the first string and second string is chattering while the third and fourth string is cold”, which presents the different voice of single and double strings.

Tough \&Tender. In the early stage of classic music of China, they all emphasize the rhyme of music, which lays the soul of national music. Rhyme refers to mutual integration of various sounds and is produced by the lingering sound of music, which presents the feminine beauty of classic music in China.

Pipa music often expresses the inner feelings of characters by lyrical melody. For example, Pipa music, Xunyang Night Moon and The Lofty Moon all mainly have lyrical melody and express people's inner feelings with moon and produces strong rhyme beauty during playing so as to fully present the feminine beauty of Pipa music.

\section{Pipa teaching and performance under the guidance of musical aesthetics}

Musical aesthetics can best present its aesthetics. Aesthetical concept refers to that a kind of aesthetic representation of the ideology formed by imagination which can bring many thoughts instead of integration with any clear concepts. Its meaning lies in that it can present various imaginations of people.

Application of acoustic patterns in musical aesthetics. The presentation of music is abstract, vague and diverse. Therefore, it requires presenting the objects with proper methods. However, the presentation of musical beauty lies in the beautiful forms produced during performance. However, the forms of beauty should firstly establish excellent acoustic patterns. Music has features different 
from other arts, such as sound symbol which is different from the characters in literature works as well as the lines in painting. It is a kind of acoustic forms established by proper sound forms and has strong sense of form. However, the structural form of music is that acoustics combine basic elements into basic musical forms by high and low sound. Finally, beautiful music and structural patterns form acoustic forms by basic music elements so that people can increase their inner feelings during appreciation of music. Therefore, the beauty of music should establish excellent acoustic forms so as to better present the aesthetic essence of music.

Application of acoustic patterns and spiritual connotations in aesthetics. Music is expressed to human beings by proper music forms so that it can rapidly stimulate people's inner feelings and express the musical contents. The representation of music is the results of people's inner feelings with its abstractness and diversity, which lead to the vagueness of music. The excellent hearing patterns of music can invoke people's feeling and combine it with the rich spiritual connotations of music. From the perspectives of psychology, feeling is a kind of sentiments to the objective things. While musical feeling is the core of musical content and a kind of reflection to the real society. The beauty of music often has the following four types.

(1) Elegance. Elegance is a representation of beauty and plays an important role in tradition music of China, which is coincidence with the aesthetical core of traditional music in China. For example, in early Confucius, harmony is the standard beauty while Taoism pursues the aesthetics of harmony, which makes the elegance and restraining of traditional Chinese music.

(2) Tragedy. In Chinese culture, drama is a form while tragedy is a basic form of beauty in aesthetical culture. Tragedy is necessary and turning in the historical development, which presents the shining humanity and power of virtue. The tragedy of music is a kind of sorrow feeling produced during appreciation of music.

(3) Comedy. The comedy in musical aesthetics can be divided into two types, namely negative and positive. The presentation of music has three processes. The first is to establish an excellent acoustic type; the second is to deepen people's understanding for spiritual connotations of music in rationality; the third is the fully combination of sense and reason. For example, His-Shan's Epithets on Ch'in Music, a Pipa music, proposes the combination and sound and meaning in which meaning is the musical content and sound is excellent acoustic form. Therefore, Pipa performers should make students understand the connotations of musical works before performance so as to really increase their overall understanding of music.

(4) Sublime. Sublime is also basic form of musical aesthetics, which undertakes the main content of music and make music have certain reason feelings to some extent.

\section{Conclusion}

Nowadays, with the development of musical aesthetics, the Pipa teaching develops in various aspects of society. Appreciation of Pipa from the musical aesthetics can make people love Pipa. As is known to all, Pipa is an ancient instrument with long history in China and has national artistic connotations and national spiritual connottaions. The development of Pipa should not only inherit its artistic skills but also continues its traditional national culture. Therefore, Pipa players should fully present the spiritual connotations of Pipa to students during teaching, which is not only the responsibility of educators but also the responsibility of people who are fond of Pipa.

\section{References}

[1] J.Y. Zhan. Discussion on several important links in Pipa teaching. Yuefu Xinsheng(Journal of Shenyang Music College),2007. (03).

[2] W.Y. Du. Representation of aesthetic in Pipa teaching. Yellow River of the Song, 2015.(08).

[3] Y. Zou. Aesthetic cultivation in Pipa teaching . Music Time,2014. (04). 
[4] L. Li. Application of film music aesthetics and functions in music teaching. Artistic Exploration, 2004.(S1).

[5] J. Li \& K.L. Li. Discussion of current Pipa and performance of Pipa music from aesthetic perspectives.Music Life, 2013.(04).

[6] N. Sun. Discussion of mediocre in Pipa performance.Great Stage, 2008.(03). 